http://jmscr.igmpublication.org/home/ ISSN (e)-2347-176x ISSN (p) 2455-0450

crossref DOI: https://dx.doi.org/10.18535/jmscr/v9i12.29

\title{
Effects of Vitamin E and Mefenamic Acid in the Treatment of Primary Dysmenorrhoea in Tertiary Care Hospital in Bangladesh
}

\author{
Authors \\ Dr Kanika Roy ${ }^{1 *}$, Dr Biplab Kumar Das ${ }^{2}$ \\ ${ }^{1}$ Senior Consultant, Department of Gynae and Obstetrics, 100 Bedded Upazila Health Complex, Kashiani, \\ Gopalgonj, Bangladesh \\ ${ }^{2}$ Assistant Professor, Department of Cardiology, Sheikh Sayera Khatun Medical College, Gopalgonj, \\ Bangladesh \\ *Corresponding Author \\ Dr Kanika Roy
}

\begin{abstract}
Background: In various research, vitamin $E$ and mefenamic supplementation has been suggested as a viable treatment for primary dysmenorrhea.

Objective: To see the effects of Vitamin $E$ and mefenamic acid in primary dysmenorrhoea.

Methods: Sheikh Sayera Khatun Medical College and Hospital, Gopalganj conducted this observational type of prospective study. Where information was gathered between 1st April 2019 to 31st March 2020.

During the research, a total of 40 Female OPD patients in Sheikh Sayera Khatun Medical College and Hospital, Gopalganj, who fulfilled the selection criteria were the study sample. Purposive sampling was used to acquire the samples according to the inclusion criteria. All data were coded and entered into SPSS-23 for further analysis. The statistics used were both descriptive and inferential. Statistics used to describe data included frequency distribution, percent, mean, and standard deviation; graphs; tables; and figures; and inferential statistics.

Results: VAS score was significantly decreased from baseline to end of treatment at 3rd cycle (7.40 \pm 0.98 to $3.70 \pm 0.72)$ for vitamin $E$ group and $(7.05 \pm 0.75$ to $3.52 \pm 0.55)$ for mefenamic acid group. The percentage reduction of VAS was $49.60 \%$ and $49.51 \%$ at 3rd cycle. The Cox Menstrual Symptom Scale score significantly decreased from baseline to end of treatment at $3 \mathrm{rd}$ cycle $(3.88 \pm 0.40$ to $1.25 \pm$ 0.44).The percentage reduction of CMSS score was $67.50 \%$ and $65.83 \%$ at 3 rd cycle.

Conclusion: As both Vitamin E and Mefenamic acid shows significant reduction in pain intensity in primary dysmenorrhoea without any difference between two treatment groups. So, in clinical practice, Vitamin E may be a useful alternative to Mefenamic acid in primary dysmenorrhoea.

Keywords: Primary dysmenorrhoea, Mefenamic acid, Vitamin E.
\end{abstract}

\section{Introduction}

Every woman's menstrual period is a natural occurrence that occurs throughout her reproductive period. Dysmenorrhoea is the term for cramping pain that occurs during menstruation. Pain is most commonly felt in the suprapubic area, but it can also radiate to the backs of the legs or the lower back, and it is frequently accompanied by other biological symptoms such as dizziness, fatigue, sweating, backache, headache, nausea, vomiting, and diarrhoea, all of which occur just before or during 
menstruation. Primary dysmenorrhoea is pain in the uterus produced by menstruation but not by any known pelvic ailment ${ }^{[1]}$. It appears $1-2$ years after menarche and is associated with normal ovulatory cycles ${ }^{[2]}$. Dysmenorrhoea induced by uterine or pelvic illness is known as secondary dysmenorrhoea $^{[3]}$. The majority of pain is caused by endometriosis and adenomyosis ${ }^{[5]}$. The exact source of pain in primary dysmenorrhoea is unknown. Myometrial contractions, which are induced by prostaglandins produced in the uterine endometrium and occur throughout the first 48 hours of menstruation, cause the pain ${ }^{[2]}$. In dysmenorrhoea, the menstrual fluid has a high concentration of Prostaglandin (PG) F2, which causes uterine blood vessel constriction, ischemia, and increased uterine smooth muscle contraction, resulting in dysmenorrhoeic pain ${ }^{[6,7]}$. Nonsteroidal anti-inflammatory drugs (NSAIDs), oral contraceptives, calcium channel blockers, and progesterone, among other things, should be utilized to lower uterine prostaglandin synthesis, given the aetiopathogenesis of primary dysmenorrhoea. $^{[8]}$ NSAIDs reduce prostaglandin production by blocking the iso-enzymes of the cyclooxygenase (COX) family, which catalyze the synthesis of prostaglandins from arachidonic $\operatorname{acid}^{[7]}$. In addition to their therapeutic effects, NSAIDs can cause side symptoms such as heartburn, blurred vision, dizziness, headache, constipation, diarrhea, lethargy, dysuria, drowsiness, anorexia, nausea, skin acne, vomiting, and gastrointestinal bleeding ${ }^{[8]}$.

In $1922^{[9]}$ the role of Vitamin $\mathrm{E}$ in nutrition and fertility was established for the first time. Vitamin E works by inhibiting the enzymes phospholipase A2 and cyclooxygenase 2 to prevent the production of arachidonic acid and the conversion of arachidonic acid to prostaglandin. Protein kinase $\mathrm{C}$ and an increase in intracellular calcium concentration are thought to govern phospholipase A2 activation.In the bovine brain, vitamin $\mathrm{E}$ inhibits protein kinase $\mathrm{C}$, resulting in an increase in internal opioids and pain relief ${ }^{[10,11]}$. Vitamin E's antioxidant activity may reduce phospholid peroxidation, hence inhibiting the release of arachidonic acid and its conversion to prostaglandins $^{[12]}$. Even after intake of 300 $\mathrm{mg} /$ day for 23 years ${ }^{[13]}$, vitamin $\mathrm{E}$ at a dose of 400 units per day for five days helps to significantly reduce the severity of pain in the treatment of dysmenorrhoea $^{[2,12-14]}$. Recently several studies revealed that Vitamin $\mathrm{E}$ is effective in reduction of pain in dysmenorrhoea. It has also absence of significant side effects in therapeutic doses.

Mefenamic acid is a conventional and nonselective NSAID. It is easily accessible over the counter and is widely used by most local adolescents and adults for dysmenorrhoea. The dosage is $500 \mathrm{mg}$ to be taken orally three times/day after meal ${ }^{[15]}$. Vitamin $\mathrm{E}$ has a significant effect on dysmenorrhoea, equal to Mefenamic acid, which is a well-known medication for the treatment of dysmenorrhea ${ }^{[16]}$.

The therapeutic effect of Vitamin E in primary dysmenorrhoea was studied in several countries in the world and these studies inspired to see the effect of same drug in our community. So this study was designed to observe the effectiveness of Vitamin E and Mefenamic acid in the treatment of primary dysmenorrhoea.

\section{Objective}

To study the effects of Vitamin E and Mefenamic acid in primary dysmenorrhoea among OPD patients.

\section{Methodology}

Department of Obstetrics and Gynaecology, Sheikh Sayera Khatun Medical College and Hospital, Gopalganj conducted this observational type of prospective study. Where information was gathered between 1st April 2019 to 31st March 2020. During the research, a total of 40Female OPD patients in Sheikh Sayera Khatun Medical College and Hospital, Gopalganj who fulfilled the selection criteria were the study sample. Purposive sampling was used to acquire the samples according to the inclusion criteria. All data were coded and entered into SPSS-23 for further 
analysis. The statistics used were both descriptive and inferential. Statistics used to describe data included frequency distribution, percent, mean, and standard deviation; graphs; tables; and figures; and inferential statistics.

\section{Results}

In table-1 shows age distribution of the study group where the patients were belong to 19-24 years. Mean \pm SD of the age was $20.40 \pm 1.46$ years. while the mean age of $20.15 \pm 1.49$ years in Mefenamic acid treated group. The mean age of Vitamin E treated group and Mefenamic acid treated group did not differ significantly $(\mathrm{t}=0.756$; $\mathrm{p}=0.452$ ) suggesting an age matched study. The following table is given below in detail:

Table-1: Age distribution of the study group

\begin{tabular}{|l|c|c|c|}
\hline Age Range & $\begin{array}{c}\text { Mefenamic Acid group } \\
\text { Mean } \pm \text { SD }\end{array}$ & $\begin{array}{c}\text { Vitamin E group } \\
\text { Mean } \pm \text { SD }\end{array}$ & P value \\
\hline $19-24$ years & $20.15 \pm 1.49$ & $20.40 \pm 1.46$ & 0.452 \\
\hline
\end{tabular}

Table 2 shows the mean height $(\mathrm{cm})$ of the Vitamin E treated group was $156.43 \pm 4.73$; whereas the mean height of the Mefenamic acid treated group was $155.99 \pm 4.79$. The mean height of the participants did not differ significantly between Vitamin E treated group and Mefenamic acid treated group $(\mathrm{t}=0.418 ; \mathrm{p}=0.677)$.

The mean weight $(\mathrm{Kg})$ of the Vitamin $\mathrm{E}$ treated group was $53.97 \pm 6.05$; whereas the mean height of the Mefenamic acid treated group was $55.90 \pm$ 7.09. The mean weight of the participants did not differ significantly between Vitamin E treated group and Mefenamic acid treated group ( $\mathrm{t}=$ 1.307; $\mathrm{p}=0.195)$.

The mean BMI $(\mathrm{Kg} / \mathrm{M} 2)$ of the Vitamin E treated group was $22.09 \pm 2.59$; whereas the mean BMI of the Mefenamic acid treated group was $22.94 \pm$ 2.42. The mean BMI of the participants did not differ significantly between Vitamin $\mathrm{E}$ treated group and Mefenamic acid treated group $(\mathrm{t}=1.514$; $\mathrm{p}=0.134)$.

Table 2: Distribution of patients by anthropometric status

\begin{tabular}{|l|c|c|c|}
\hline Anthropometric status & $\begin{array}{c}\text { Vitamin E group } \\
\text { Mean } \pm \text { SD }\end{array}$ & $\begin{array}{c}\text { Mefenamic Acid group } \\
\text { Mean } \pm \text { SD }\end{array}$ & P value \\
\hline Height $(\mathrm{Cm})($ Mean \pm SD) & $156.43 \pm 4.73$ & $155.99 \pm 4.79$ & 0.677 \\
\hline Weight $(\mathrm{Kg})($ Mean \pm SD) & $53.97 \pm 6.05$ & $55.90 \pm 7.09$ & 0.195 \\
\hline BMI $\left(\mathrm{Kg} / \mathrm{M}^{2}\right)($ Mean $\pm \mathrm{SD})$ & $22.09 \pm 2.59$ & $22.94 \pm 2.42$ & 0.134 \\
\hline
\end{tabular}

In table-3 shows the visual analogue scale score (mean \pm SD) was $7.40 \pm 0.98$ at baseline before the initiation of treatment which decreased to 6.28 \pm 0.72 at 1 st cycle, to $5.00 \pm 0.91$ at 2 nd cycle and to $3.70 \pm 0.72$ at 3 rd cycle. In Mefenamic acid treated group, the visual analogue scale score (mean $\pm \mathrm{SD}$ ) was $7.05 \pm 0.75$ at baseline before the initiation of treatment which decreased to 5.90 \pm 0.71 at 1 st cycle, to $4.75 \pm 0.71$ at 2 nd cycle and to $3.52 \pm 0.55$ at 3 rd cycle. The Cox Menstrual
Symptom Scale score (mean \pm SD) was $3.88 \pm$ 0.40 at baseline before the initiation of treatment which decreased to $3.12 \pm 0.69$ at 1 st cycle, to $2.02 \pm 0.83$ at 2 nd cycle and to $1.25 \pm 0.44$ at $3 \mathrm{rd}$ cycle. In Mefenamic acid treated group, the Cox Menstrual Symptom Scale score (mean \pm SD) was $3.95 \pm 0.22$ at baseline before the initiation of treatment which decreased to $3.08 \pm 0.42$ at $1^{\text {st }}$ cycle, to $2.10 \pm 0.50$ at $2^{\text {nd }}$ cycle and to $1.35 \pm 0.48$ at $3{ }^{\text {rd }}$ cycle. 
Table-3: VAS scores and CMSS scores of the participants at baseline and different cycles of treatment

\begin{tabular}{|l|c|c|c|}
\hline VAS scores & $\begin{array}{c}\text { Vitamin E Group } \\
\text { Mean } \pm \text { SD }\end{array}$ & $\begin{array}{c}\text { Mefenamic Acid group } \\
\text { Mean } \pm \text { SD }\end{array}$ & P value \\
\hline Baseline & $7.40 \pm 0.98$ & $7.05 \pm 0.75$ & 0.077 \\
\hline First Cycle & $6.28 \pm 0.72$ & $5.90 \pm 0.71$ & 0.021 \\
\hline Second Cycle & $5.00 \pm 0.91$ & $4.75 \pm 0.71$ & 0.173 \\
\hline Third Cycle & $3.70 \pm 0.72$ & $3.52 \pm 0.55$ & 0.228 \\
\hline CMSS scores & Mean \pm SD & Mean \pm SD & P value \\
\hline Baseline & $3.88 \pm 0.40$ & $3.95 \pm 0.22$ & 0.306 \\
\hline First Cycle & $3.12 \pm 0.69$ & $3.08 \pm 0.42$ & 0.695 \\
\hline Second Cycle & $2.02 \pm 0.83$ & $2.10 \pm 0.50$ & 0.626 \\
\hline Third Cycle & $1.25 \pm 0.44$ & $1.35 \pm 0.48$ & 0.335 \\
\hline
\end{tabular}

Figure -1 shows the percentage reduction of VAS score was in Vitamin E group $14.50 \%$ at 1 st cycle, to $32.06 \%$ at 2 nd cycle and to $49.60 \%$ at 3 rd cycle of treatment. In Mefenamic acid treated group, the percentage reduction of VAS was $15.81 \%$ at 1 st cycle, to $32.16 \%$ at 2 nd cycle and to $49.51 \%$ at 3rd cycle of treatment

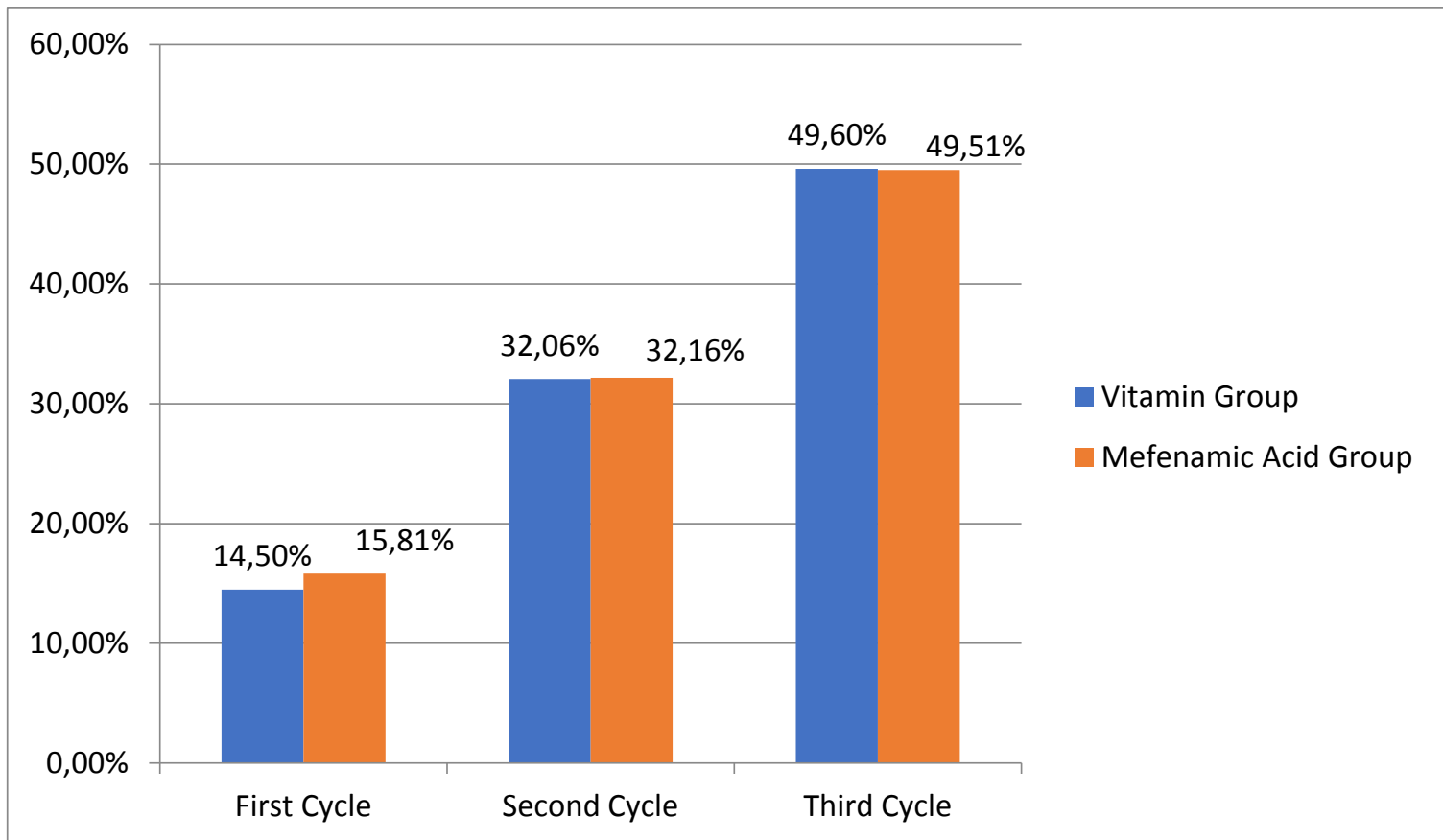

Figure-1: Percentage reduction of VAS score estimated at different cycles

In figure-2 shows the percentage reduction of CMSS score in Vitamin $\mathrm{E}$ treated group was $18.96 \%$ at 1 st cycle, to $47.08 \%$ at 2 nd cycle and to $67.50 \%$ at 3 rd cycle of treatment. The percentage reduction of CMSS score in Mefenamic acid treated group was $22.08 \%$ at 1 st cycle, to $46.88 \%$ at 2 nd cycle and to $65.83 \%$ at 3 rd cycle of treatment. 


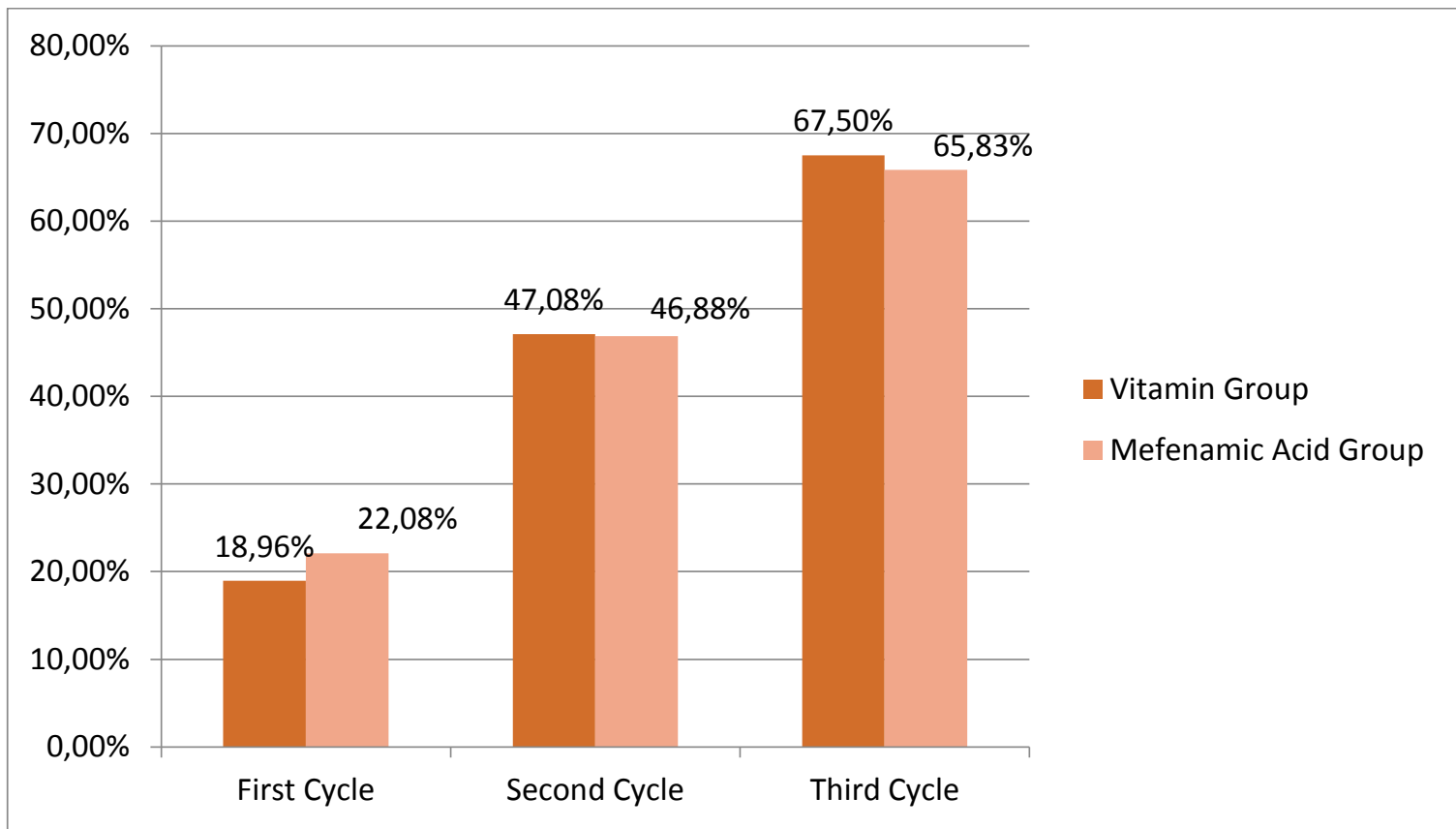

Figure-2: Percentage reduction of CMSS score estimated at different cycles

The recorded adverse effects were heart burn $(0.0 \%)$ vs $(22.5 \%)$ which was significantly fewer in Vitamin $\mathrm{E}$ treated group in respect to Mefenamic acid treated group; $\mathrm{p}=0.002$, while nausea and or vomiting (12.5\%) vs (27.5\%); $\mathrm{p}=0.094$ and dizziness $(7.5 \%)$ vs $(2.5 \%) ; \mathrm{p}=0.615$ did not differ significantly between two treatment groups.

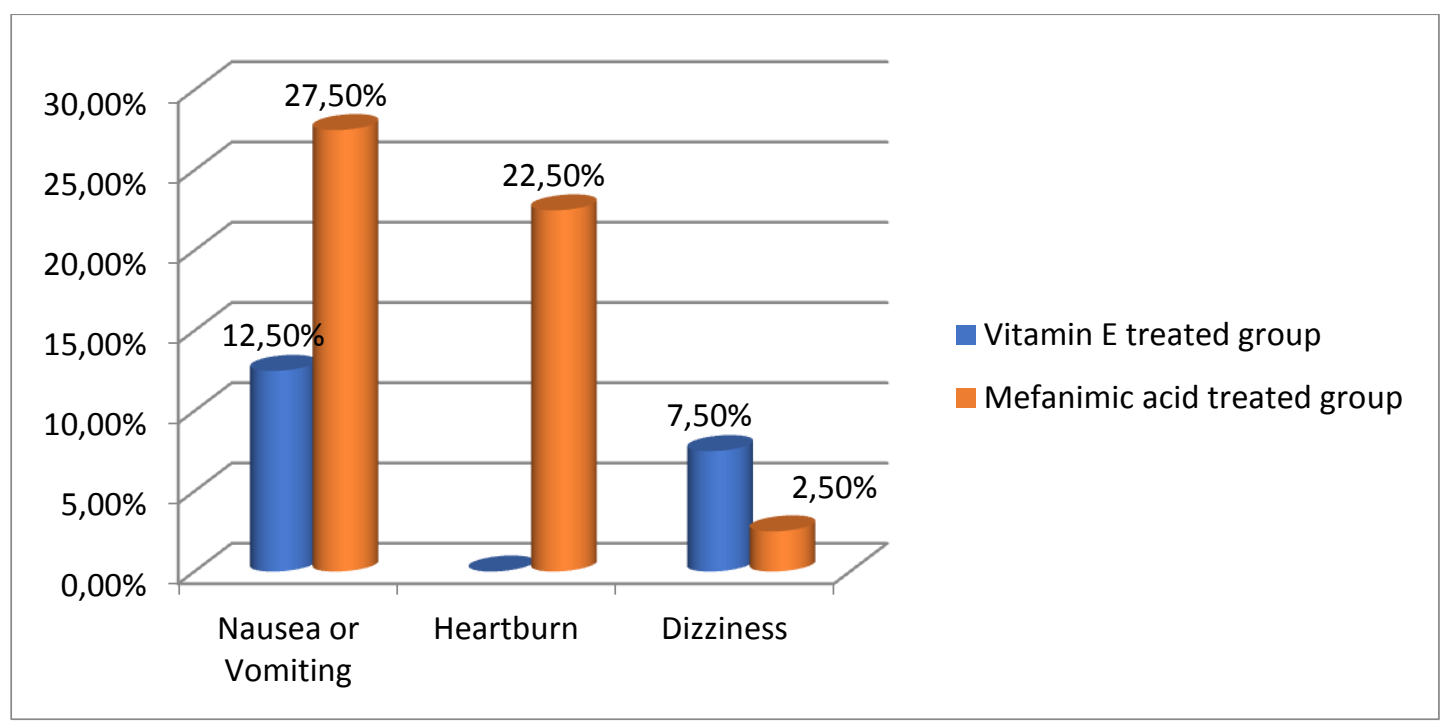

Figure 3: Patients with different types of adverse effects

\section{Discussion}

Vitamin E inhibits the release of arachidonic acid and the conversion of arachidonic acid to PG via an action on the enzymes phospholipase $\mathrm{A} 2$ and cyclooxygenase $^{[17]}$. Several studies reported that treatment with vitamin E therapy daily significantly reduced the severity of pain in primary dysmenorrhoea ${ }^{[17,18]}$. A single study compared the effect Mefenamic acid and Vitamin $E$ in the treatment of dysmenorrhoea with similar efficacy. In this study the age of the patients ranged from 19 to 24 years with the mean age (Mean \pm SD) of $20.40 \pm 1.46$ years in Vitamin $\mathrm{E}$ treated group; while the age of the patients ranged from 17 to 23 years with the mean age of $20.15 \pm$ 1.49 years in Mefenamic acid treated group. The 
mean age of Vitamin $E$ treated group and Mefenamic acid treated did not differ significantly $(\mathrm{p}=0.452)$ suggesting an age matched study. Ibrahim et al., (2015) reported the age of the female patients $21.40 \pm 1.4$ years. This was consistent with the present study. In another study the mean age of the patients was $19.43( \pm 3.9)$ years with variation of participants aged 16 to 24 years $^{[19]}$ Age at enrolment of patients with dysmenorhoea was $17.0 \pm 0.7$ years was also reported in the study of Ziae et al., (2001).

In the present study the mean height of the Vitamin E treated group was $156.43 \pm 4.73 \mathrm{~cm}$; whereas the mean height of the Mefenamic acid treated group was $155.99 \pm 4.79 \mathrm{~cm}$. The mean height of the participants did not differ significantly between Vitamin E treated group and Mefenamic acid treated group $(\mathrm{p}=0.677)$. Masoumi et al., (2016) reported mean height of the patients with dysmenorrhoea was $141.63 \pm$ $3.60 \mathrm{~cm}$.

This study demonstrated that the mean weight of the Vitamin E treated group was $53.97 \pm 6.05 \mathrm{Kg}$; whereas the mean height of the Mefenamic acid treated group was $55.90 \pm 7.09 \mathrm{Kg}$. The mean weight of the participants did not differ significantly between Vitamin $\mathrm{E}$ treated group and Mefenamic acid treated group $(p=0.195)$. Mean weight of patients with dysmenorrhoea was 55.09 $\pm 5.81 \mathrm{~kg}$ reported in the study of Masoumi et al., (2016) which was close to the result of present study.

In this study the mean BMI of the Vitamin E treated group was $22.09 \pm 2.59 \mathrm{Kg} / \mathrm{M} 2$; whereas the mean BMI of the Mefenamic acid treated group was $22.94 \pm 2.42 \mathrm{Kg} / \mathrm{M} 2$. The mean BMI of the participants did not differ significantly between Vitamin E treated group and Mefenamic acid treated group $(\mathrm{p}=0.134)$. Farahani et al., (2017) reported that the BMI of the women with dysmenorrhoea was $21.2 \pm 3.8$. Ozgoli et al., (2009) found that the BMI of the women with dysmenorrhoea treated with Mefenamic acid was $22.2 \pm 2.2 \mathrm{~kg} / \mathrm{m} 2$.
In this study the visual analogue scale score was decreased from the value recorded before initiation of treatment to first cycle, second cycle and third cycle. The overall reduction of visual analogue scale score from baseline to end of treatment was significant $(\mathrm{p}<0.001)$ in Vitamin $\mathrm{E}$ treated group. Post hoc analysis revealed that VAS score decreased significantly at first cycle of treatment with Vitamin $\mathrm{E}$ from baseline and further decreased in subsequent cycle (baseline vs 1st cycle; $\mathrm{p}<0.001 ;$ baseline vs 2 nd cycle, $\mathrm{p}<0.001$; baseline vs 3 rd cycle, $\mathrm{p}<0.001$; 1 st cycle vs 2 nd cycle, $\mathrm{p}<0.001$; 1 st cycle vs 3 rd cycle, $\mathrm{p}<0.001$; 2nd cycle vs 3rd cycle, $\mathrm{p}<0.001$ ). Similarly in Mefenamic acid group, the visual analogue scale score was decreased from the value recorded before initiation of treatment to first cycle, second cycle and third cycle. The overall reduction of visual analogue scale score from baseline to end of third cycle of treatment was significant $(p<0.001)$ in Mefenamic acid treated group. Post hoc analysis revealed that VAS score decreased significantly at first cycle of treatment with Mefenamic acid from baseline and further decreased in subsequent cycle (baseline vs 1 st cycle; $\mathrm{p}<0.001$; baseline vs 2nd cycle, $\mathrm{p}<0.001$; baseline vs 3rd cycle, $\mathrm{p}<0.001$; 1 st cycle vs 2 nd cycle, $\mathrm{p}<0.001 ; 1$ st cycle vs 3 rd cycle, $\mathrm{p}<0.001$; 2 nd cycle vs 3 rd cycle, $\mathrm{p}<0.001)$. There was no statistically significant difference found between two groups before initiation of treatment) $(\mathrm{p}=0.077)$, the 2nd $(\mathrm{p}=0.173)$ and 3rd cycle $(\mathrm{p}=0.228)$ of treatment; but significant difference was observed at 1 st cycle of treatment $(\mathrm{p}=0.021)$. In a study by Vilvapriya and Vinodhini, (2017), 200 units of Vitamin E twice daily were given in the treatment of primary dysmenorrhoea. The treatment began two days before the beginning of menstruation and continued through the first three days of bleeding. The severity of pain and duration of pain before and after the treatment was studied. There was a significant difference between the pre- and post-treatment periods in terms of pain severity by VAS score $(\mathrm{p}=0.720$ and $\mathrm{p}=0.002$, respectively). Nayeban et al., (2014) 
found that the pain intensity in the vitamin $\mathrm{E}$ was 55.7742 before the treatment started and reduced to 45.1398 after the treatment. The reduction of pain measured by VAS score from before the treatment to after the treatment showed a significant difference $(p<0.001)$. In a study by Ziaei et al., (2001) on the effect of Vitamin E on dysmenorrhoea, 500 IU Vitamin E was used for 5 days during the beginning of menstruation and was compared with placebo. They showed that both Vitamin E and placebo reduced the pain of dysmenorrhoea but that the reduction was greater in the Vitamin E group. The result of this study is in agreed with the present study, but our dosage of Vitamin E was lower. In another study by Ziaei et al., (2005) 400 IU Vitamin $E$ was used for 4 months. The conclusion was that pain severity in month 4 was less than the pain reported in month 2 after treatment, indicating a positive effect of Vitamin E throughout the treatment and that more prolonged use had a greater effect. This study agreed with our study findings ${ }^{[22]}$. A study by Kashanian et al., (2013) used 400 IU/day of Vitamin E starting 2 days before the beginning of menstruation and continuing for a total of 5 days, for 2 consecutive cycles reveled a significant reduction in severity of pain ( $p=0.046$ ) when 400 units of Vitamin $\mathrm{E}$ per day was given for 5 days. Shirvani et al., (2015) found that the pain intensity in the Mefenamic was $55.03 \pm 14.95$ in the onset of the study. It was $39.01 \pm 17.77$ in the first month and $33.75 \pm 17.71$ in the second month. Repeated measurement showed a significant difference in pain intensity within the groups by time $(p<0.05)$. Farahani et al., (2017) found that the comparison of variations of pain pre-treatment and post-treatment in the Mefenamic acid group revealed statically significant difference pain severity measured by VAS score with p-value of comparison between the first month and control cycle $(\mathrm{p}<0.001)$, comparison between the second month and control cycle $(\mathrm{p}<0.001)$; and comparison between the first month and second month $(\mathrm{p}<0.001)$.
This study also showed the percentage change in VAS score estimated at first, second and third cycle of treatment in comparison to before initiation of treatment. In Vitamin E treated group, the percentage improvement of VAS score was $14.50 \%$ at first cycle, $32.06 \%$ at second cycle and $49.60 \%$ at third cycle of treatment. The overall difference from baseline to last cycle of treatment was significant $(p<0.001)$. In Mefenamic acid treated group, the percentage improvement of VAS score was $15.81 \%$ at first cycle, to $32.16 \%$ at second cycle and to $49.51 \%$ at third cycle of treatment. The overall percentage improvement of VAS score from baseline to completion of treatment was significant $(\mathrm{p}<0.001)$. But when percentage reduction of VAS score of the two treatments were compared, there were no significant percentage reduction of VAS score in Vitamin E treated group compared to Mefenamic acid treated group estimated at first cycle $(\mathrm{p}=0.555)$, at second cycle $(\mathrm{p}=0.955)$ and at third cycle $(p=0.968)$ of treatment. From the above findings of changes in VAS score it was summarized that pain was reduced in both Vitamin E and Mefenamic acid treated group with significantly more pain reduction in first cycle in Mefenamic acid treated group but similar effect was seen thereafter in both groups. In a study by Vilvapriya and Vinodhini, (2017), 200 units of Vitamin E twice daily were given in the treatment of primary dysmenorrhoea. The study showed that there was significant difference in percent of reduction of pain of $57.8 \pm 22.8$ in Vitamin E group at the end of treatment. Other available studies did not show the percent reduction of pain in Mefenamic acid.

In this study the Cox Menstrual Symptom Scale score was decreased from the value recorded before initiation of treatment to first cycle, second cycle and third cycle. The overall reduction of Cox Menstrual Symptom Scale score from the score of before initiation of treatment to cessation of treatment was significant $(\mathrm{p}<0.001)$ in Vitamin E treated group. Post hoc analysis revealed that CMSS score decreased significantly at first cycle 
of treatment with Vitamin $\mathrm{E}$ from baseline and further decreased in subsequent cycle (baseline vs 1st cycle; $\mathrm{p}<0.001$; baseline vs 2nd cycle, $\mathrm{p}<0.001$; baseline vs 3rd cycle, $\mathrm{p}<0.001$; 1 st cycle vs 2 nd cycle, $\mathrm{p}<0.001 ; 1$ st cycle vs 3rd cycle, $\mathrm{p}<0.001$; 2nd cycle vs 3rd cycle, $\mathrm{p}<0.001$ ). Similarly, Mefenamic acid group, the Cox Menstrual Symptom Scale score was decreased from the value recorded before initiation of treatment to first cycle, second cycle and third cycle. The overall reduction of Cox Menstrual Symptom Scale score from baseline to third cycle of treatment was significant $(\mathrm{p}<0.001)$ in Mefenamic acid treated group. Post hoc analysis revealed that CMSS score decreased significantly at first cycle of treatment with Mefenamic acid from baseline and further decreased in subsequent cycle (baseline vs 1st cycle; $\mathrm{p}<0.001$; baseline vs 2nd cycle, $\mathrm{p}<0.001$; baseline vs 3rd cycle, $\mathrm{p}<0.001 ; 1$ st cycle vs 2nd cycle, $\mathrm{p}<0.001 ; 1$ st cycle vs 3rd cycle, $\mathrm{p}<0.001$; 2nd cycle vs 3rd cycle, $\mathrm{p}<0.001)$. When change in the Cox Menstrual Symptom Scale score in the two treatments groups were compared, no significant difference was observed before initiation of treatment $(\mathrm{p}=0.306)$, at first cycle $(\mathrm{p}=0.695)$, second cycle $(\mathrm{p}=0.626)$ and at third cycle $(\mathrm{p}=0.335)$ of treatment. In a study by Vilvapriya and Vinodhini, (2017), 200 units of Vitamin E twice daily were given in the treatment of primary dysmenorrhoea. The treatment began two days before the beginning of menstruation and continued through the first three days of bleeding. There was a significant difference between the pre- and post-treatment periods in terms of pain duration by CMSS score ( $\mathrm{p}=0.514$ and $\mathrm{p}=0.027$, respectively) in Vitamin E group. Nayeban et al., (2014) compared the mean of pain duration before and after the treatment, based on CMSS and revealed that pain duration before the treatment was 1.9749 hour and after the treatment was 1.5878 hour. There was significantly reduction of duration of pain from before treatment and after treatment $(\mathrm{p}=0.002)$.
This study also showed the percentage in CMSS estimated at first, second and third cycle of treatment in comparison to before initiation of treatment. In Vitamin $\mathrm{E}$ treated group, the percentage improvement of CMSS score was $18.96 \%$ at first cycle, $47.08 \%$ at second cycle and $67.50 \%$ at third cycle of treatment. The overall difference from baseline to end of treatment was significant $(p<0.001)$. The percentage reduction of CMSS score was also noted in Mefenamic acid treated group with $22.08 \%$ at first cycle, $46.88 \%$ at second cycle and $65.83 \%$ at third cycle of treatment. The overall percentage reduction of CMSS score from baseline to termination of treatment was significant $(\mathrm{p}<0.001)$. But when percentage reduction of CMSS reduction of the two treatments were compared, there were no significant percentage reduction of CMSS in Vitamin E treated group compared to Mefenamic acid treated group estimated at first cycle $(\mathrm{p}=0.320)$, at second cycle $(\mathrm{p}=0.959)$ and at third cycle $(p=0.520)$ of treatment. The above results indicated that changes in CMSS score was reduced in both Vitamin $\mathrm{E}$ and Mefenamic acid treated group without any significant in first, second and third cycle between two treatment groups. In a study by Vilvapriya and Vinodhini, (2017), 200 units of Vitamin E twice daily were given in the treatment of primary dysmenorrhoea. The study showed that there was significant difference in percent of reduction of duration of pain of $68.5 \pm 28.2$ in Vitamin E group at the end of treatment. Other available studies did not show the percent reduction of pain in Mefenamic acid.

Safari et al. (2006) showed that Vitamin E has a significant effect on dysmenorrhoea, equal to Mefenamic acid, which is a well-known medication for the treatment of dysmenorrhoea; the results are similar to the findings of the present study. One study shows that Mefenamic Acid is a suitable drug for the treatment of primary dysmenorrhoea, especially in those suffering from moderate pain ${ }^{[20]}$. In another study, Mefenamic Acid has been proposed as a dominant treatment for dysmenorrhoea ${ }^{[21]}$ 


\section{Conclusion}

Based on study findings, it can be concluded that Vitamin $\mathrm{E}$ is effective in the treatment of primary dysmenrrhoea. Vitamin $\mathrm{E}$ is free from adverse effects. The Vitamin $\mathrm{E}$ has less side effects. Vitamin $\mathrm{E}$ is the effective and the safe option for the treatment of primary dysmenorrhoea.

\section{References}

1. Kaur S, Sheoran P, Sarin J. Assessment and comparison of dysmenorrhoea in terms of severity of pain and utilization of non steroid anti-inflammatory drugs among unmarried and married women, International Journal of Caring Sciences, 2015; 8(3): 737-745.

2. Vilvapriya $S$, Vinodhini S. Vitamin $E$ in the treatment of primary dysmenorrhoea, International Journal of Reproduction, Contraception, Obstetrics and Gynecology, 2018; 7(6): 2257-2261.

3. Gebeyehu MB, Mekuria AB, Tefera YG, Andarge DA, Debay YB, Bejiga GS, et al.. Prevalence, Impact, and Management Practice of Dysmenorrhoea among University of Gondar Students, Northwestern Ethiopia: A Cross-Sectional Study, International Journal of Reproductive Medicine, 2017: 1-8. [ DOI: 10.1155/2017/3208276 ]

4. Malhotra N, Kumar P, Malhotra J, Bora NM, Mittal P. Jeffcoate's Principle of Gynaecology, Eighth Edition, Jaypee Brothers Medical Publications, New Delhi, 2014: 579.

5. Shirvani MA, Motahari-Tabari N, Alipour A. The effect of Mefenamic Acid and Ginger on Pain Relief in Primary Dysmenorrhoea: A Randomized Clinical Trial, Archives of Gynecology and Obstetrics, 2015; 291(6): 1277-1281.

6. Marjoribanks J, Ayeleke RO, Farquhar C, Proctor M. 2015. Nonsteroidal antiinflammatory drugs for dysmenorrhoea, The Cochrane Database of Systematic
Reviews, 2015 July 30;2015(7), CD001751: 1-137 [doi: 10.1002/14651858.CD001751.pub3]

7. Iacovides S, Baker FC, Avidon I. The 24-h progression of menstrual pain in women with primary dysmenorrhoea when given diclofenac potassium: a randomized, double-blinded, placebo-controlled crossover study, Archives of Gynecology and Obstetrics, 2014;289(5): 993-1002.

8. Farahani ËLA, Hasanpoor-Azghdy SB, Kasraei H, Heidari T. 2017. Comparison of the effect of honey and Mefenamic acid on the severity of pain in women with primary dysmenorrhoea. Archives of Gynecology and Obstetrics, 296(2): 277283. 18. Mutalip SSM, Ab-Rahim S and Rajikin MH. Vitamin E as an Antioxidant in Female Reproductive Health, Antioxidants, 2018 February;7(22):2-15. [doi:10.3390/antiox7020022]

9. Hayes EC, Rock JA. 2002. Cox-2 inhibitors and their role in gynecology, Obstetrics and Gynecology, 57(11): 768780.

10. Nayeban S. Jafarnejad F, Nayeban S, Sefidgaran A. A Comparison of the Effects of Vitamin E and Vitamin B1 on the Severity and Duration of Pain in Primary Dysmenorrhoea, Journal of Midwifery and Reproductive Health, 2014; 2(2): 143-146.

11. Kashanian M, Lakeh MM, Ghasemi A, Noori S. Evaluation of the effect of vitamin $\mathrm{E}$ on pelvic pain reduction in women suffering from primary dysmenorrhoea, Journal of Reproductive Medicine, 2013; 58(1-2): 34-38.

12. Ziaei S, Zakeri M, Kazemnejad A. A randomised controlled trial of vitamin $\mathrm{E}$ in the treatment of primary dysmenorrhoea, British Journal of Obstetrics and Gynaecology, 2005; 112(4): 466-469

13. Satyanarayan U, Chakrapani U. Biochemistry, Fourth Edition, Reed Elsevier India Private Limited and Books 
and Allied (P) Ltd, 8/1 Chintamoni Das Lane, Kolkata 700009, India, ISBN: 9788131236017, 9788131237137,15 June $2013 ; 129$.

14. Azlin MIN, Maryasalwati I, Norzilawati MN, Mahdy ZA, Jamil MA, Rashid MRZ. The efficacy of etoricoxibvsMefenamic acid in the treatment of primary dysmenorrhoea: A randomised comparative trial, Journal of Obstetrics and Gynaecology, 2008; 28(4): 424-426.

15. Azlin MIN, Maryasalwati I, Norzilawati MN, Mahdy ZA, Jamil MA, Rashid MRZ. 2008. The efficacy of etoricoxibvs Mefenamic acid in the treatment of primary dysmenorrhoea: A randomised comparative trial. Journal of Obstetrics and Gynaecology, Vol. 28, No. 4, pp. 424426.

16. Safari A, Shah Rezaei GR, Damavandi A. 2006. Comparison of the effects of vitamin $\mathrm{E}$ and Mefenamic acid on the severity of primary dysmenorrhoea. Annals of Military and Health Sciences Research, Vol. 4, No. 1, pp. 735-738.

17. Masoumi SZ, Asl HR, Poorolajal J, Panah MH, Oliaei SR. Evaluation of Mint Efficacy Regarding Dysmenorrhoea in Comparison with Mefenamic Acid: A Double Blinded Randomized Crossover Study, Iranian Journal of Nursing Midwifery Research, 2016; 21(4): 363-367

18. Asif M. Study of Anthranylic Acid Derivatives: Mefenamic Acid and Its Various Analogues, American Journal of Medicine Studies, 2014; 2(1): 24-30.

19. Ziaei S, Zakeri M, Kazemnejad A. 2005. A randomised controlled trial of vitamin $\mathrm{E}$ in the treatment of primary dysmenorrhoea. British Journal of Obstetrics and Gynaecology, Vol. 112, No.4, pp. 466469.
20. Masoumi SZ, Asl HR, Poorolajal J, Panah MH, Oliaei SR. 2016. Evaluation of mint efficacy regarding dysmenorrhoea in comparison with Mefenamic acid: A double blinded randomized crossover study. Iranian Journal of Nursing Midwifery Research, Vol. 21, No. 4, pp. 363-367.

21. Asif M. 2014. Study of Anthranylic Acid Derivatives: Mefenamic Acid and Its Various Analogues. American Journal of Medicine Studies, Vol. 2, No. 1, pp. 24-30. 